STRUCTURE AND FUNCTION

OF CEREBRAL COMMISSURES 


\title{
STRUCTURE AND FUNCTION OF CEREBRAL COMMISSURES
}

\author{
Edited by \\ I. STEELE RUSSELL \\ MRC Unit on Neural Mechanisms of Behaviour \\ M. W. VAN HOF \\ Department of Physiology 1, Erasmus University, Rotterdam \\ G. BERLUCCHI \\ Institute of Physiology, University of Pisa
}


(C) I. Steele Russell, M. W. van Hof and G. Berlucchi 1979

Softcover reprint of the hardcover 1st edition 1979

All rights reserved. No part of this publication may be reproduced or transmitted, in any form or by any means, without permission

First published 1979 by

THE MACMILLAN PRESS LTD

London and Basingstoke

Associated companies in Delhi Dublin

Hong Kong Johannesburg Lagos Melbourne

New York Singapore and Tokyo

Typeset by

Reproduction Drawings Ltd., Sutton, Surrey

British Library Cataloguing in Publication Data

Structure and Function of the Cerebral Commissures

(Conference), Rotterdam, 1977.

Structure and function of cerebral commissures.

1. Anterior commissure-Congresses

I. Russell, I Steele II. Hof, M W van

III. European Brain Behaviour Society

$596^{\prime} .01^{\prime} 88 \quad$ QP381

ISBN 978-1-349-03647-9 ISBN 978-1-349-03645-5 (eBook)

DOI 10.1007/978-1-349-03645-5

This book is sold subject to the standard conditions of the Net Book Agreement 


\section{CONTENTS}

\section{List of contributors}

viii

Preface

Introduction to the beginnings of commissure research

$\mathrm{xi}$

xii

1. Anatomy of cerebral commissures in reptiles A.H.M. Lohman and P. V. Hoogland

2. Morphological relationship established through the habenulointerpeduncular system between the right and left portions of the frog brain $M$. Kemali

3. Interocular transfer and commissure function in lower vertebrates, with special reference to fish $G$. E. Savage

4. Interocular transfer in the goldfish C. H. YeO

5. Behavioural and anatomical aspects of monocular vision in birds V. Maier

6. Do training conditions affect interocular transfer in the pigeon?

$J$. A. Graves and M. A. Goodale

7. Interhemispheric integration of visual information in the pigeona behavioural study $M$. Graf and $H$. Zeier

8. Effects of early visual deprivation on pattern discrimination learning and interocular transfer in the pigeon (Columba livia) A. Burkhalter and M. Cuénod

9. Experience and plasticity in the central nervous system G. Horn, S. P. R. Rose and P. P. G. Bateson

10. Mammalian neocortical commissures $L$. J. Garey

11. On the normal arrangement of fibres and terminals and limits of plasticity in the callosal system of the rat $J$. R. Wolff and

L. Záborszky

12. Cobalt-induced epilepsy in the rat: some studies on the mirror focus J. K. McQueen and R. C. Dow

13. Interocular transfer of visual learning in the rat I. Steele Russell, J. F. Bookman and G. Mohn

14. Some studies of interhemispheric integration in the rat

\section{Steele Russell and S. C. Morgan}

15. Ultrastructure and conduction properties of visual callosal axons of the rabbit H. A. Swadlow and S. G. Waxman

16. Interhemispheric communication between neurons in visual cortex of the rabbit H. A. Swadlow

17. Interocular transfer and interhemispheric communication in the rabbit $M$. W. van Hof

18. Commissural connections of the visual cortex of the cat D. Sanides 
19. Adult and neonatal characteristics of the callosal zone at the

boundary between areas 17 and 18 in the cat G.M. Innocenti

20. Transfer of visual information across the midline to the superior colliculus in the split-chiasm cat A. Antonini, G. Berlucchi, C. A. Marzi and J. M. Sprague

21. Altered incorporation of labelled uridine into RNA in secondary epileptic foci contralateral to primary epileptic lesions in the cat's cortex A. Cupello, R. Amore, F. Ferrillo, G. Lazzarini and G. Rosadini

22. The pharmacology of callosal transmission: a general survey C. E. Giurgea and F. Moyersoons

23. Pathways of interocular transfer in Siamese cats C. A. Marzi, M. Di Stefano and A. Simoni

24. Cutaneous and proprioceptive input to the corpus callosum in the cat T. Manzoni, G. Spidalieri and R. Caminiti

25. Commissural connections between the vestibular nuclei studied with the method of the retrograde transport of horseradish peroxidase O. Pompeiano, T. Mergner and $N$. Corvaja

26. Role of forebrain commissures in hemispheric specialisation and memory in macaques $\quad R$. W. Doty, W. H. Overman, Jr and N. Negrão

27. Interhemispheric transfer of visual information via the corpus callosum and anterior commissure in the monkey $S . R$. Butler

28. Mirror-image transfer in optic chiasm sectioned monkeys B. Starr

29. Report of a severe accuracy deficit in the split-brain monkey performing a between hand choice-RT task: evidence for a unilateral functioning hypothesis $Y$. Guiard

30. Contribution of positional and movement cues to visuomotor reaching in split-brain monkey $D$. Beaubaton, A. Grangetto and J. Paillard

31. Interhemispheric transmission of learning and of abnormal electrical discharges: why should there be differences? G. Ettlinger

32. Interfield differences in reaction times to lateralised visual stimuli in normal subjects $G$. Rizzolatti

33. Left hemifield superiority and the extraction of physiognomic information P. Bertelson, H. Vanhaelen and J. Morais

34. Consciousness after complete surgical section of the forebrain commissures in man B. Preilowski

35. Interhemispheric modulation of light difference threshold in the periphery of the visual field J. Zihl, D. von Cramon, E. Pöppel and $W$. Singer

36. A review of behavioural studies of agenesis of the corpus callosum A. D. Milner and M. A. Jeeves

37. Some limits to interhemispheric integration in cases of callosal agenesis and partial commissurotomy $M$. A. Jeeves 
38. On the role of cerebral commissures in animals L. Weiskrantz

*39. Anatomical aspects of the agenesis of the corpus callosum in man

S. Z. Stefanko and V. W. D. Schenk

Author Index

484

Subject Index 


\section{LIST OF CONTRIBUTORS AND PARTICIPANTS AT THE EBBS WORKSHOP 1977}

Amore, R., Center for Cerebral Neurophysiology, National Research Council Institute of Neurophysiopathology, University of Genoa, Italy

Antonini, A., Istituto di Fisiologia, Universita di Pisa, 56100 Pisa, Via S. Zeno 29-31, Pisa, Italy

Atal Russell, G., Wellcome Institute for the History of Medicine, 183 Euston Road, London NW1 2 BP

Bateson, P. P. G., Department of Zoology University of Cambridge, Cambridge

Beaubaton, D., Institut de Neurophysiologie et de Psychophysiologie, Departement de Psychophysiologie Generale, C.N.R.S.-INP 4-31, chemin JosephAiguier, 13274 Marseille Cedex 2, France

Beauvois, M. F., Laboratoire de Neuropsychologie INSERM U. 84, Hôpital de la Salpetrière, 47 Boulevard de l'Hôpital, 75634 Paris Cedex 13, France

Berlucchi, G., Istituto di Fisiologia, Universita di Pisa, 56100 Pisa, Via S. Zeno 29-31, Pisa, Italy

Bertelson, P., Laboratoire de Psychologie experimentale, Université Libre de Bruxelles, Avenue Adolphe Buyl 117, 1050 Bruxelles, Belgium

Bookman, J., MRC Unit on Neural Mechanisms of Behaviour, 3 Malet Place, London WC1E 7JG

Burkhalter, A., Institute for Brain Research, University of Zurich, August-Forel Strasse 1, CH-8029 Zurich, Switzerland

Butler, S., The University of Birmingham, Department of Anatomy, Medical School, Vincent Drive, Birmingham B15 2T J

Caminiti, R., Istituto di Fisiologia Umana, via Grotte di Posatora, 60100, Ancona, Italy

Corvaja, N., Istituto di Fisiologia Umana, Via S. Zeno 31, 56100 Pisa, Italy
Cuénod, M., Institute for Brain Research, University of Zurich, August-Forel Strasse 1, CH-8029 Zurich, Switzerland

Cupello, A., Center for Cerebral Neurophysiology, National Research Council Institute of Neurophysiopathology, University of Genoa, Italy

Doty, R. B., Center for Brain Research, Box 605, University of Rochester, Rochester, New York 14642, U.S.A.

Downer, J. L. deC., Department of Physiology, King Faisal University Colleges of Medicine and Medical Sciences, P.O. Box 2114 Damman, Saudi Arabia

Ettlinger, G., Institute of Psychiatry, De Crespigny Park, Denmark Hill, London SE5 8AF

Ferrilo, F., Center for Cerebral Neurophysiology, National Research Council Institute of Neurophysiopathology, University of Genoa, Italy

Garey, L. J., Institut d'Anatomie, Université de Lausanne, Rue du Bugnon 9, $\mathrm{CH}$ 1011 Lausanne, Switzerland

Giurgea, C. E., UCB, Division Pharmaceutique, 68 rue Berkendael, B-1060, Bruxelles, Belgium

Goodale, M. A., Department of Psychology, University of Western Ontario, London, Ontario, Canada

Gordon, H. W., The Aba Khoushy School of Medicine in Haifa, Department of Behavioral Biology, Gutwirth Building, Technion City, Haifa, Israel

Graf, M., Swiss Federal Institute for Technology Zurich, Department of Behavioral Science, Turnerstrasse 1, CH-8006 Zurich, Switzerland

Grangetto, A., Institut de Neurophysiologie et de Psychophysiologie, Département de Psychophysiologie Generale, C.N.R.S. INP 4-31, chemin Joseph-Aiguier, 13274 Marseille Cedex 2, France 
Graves, J. A., Psychological Laboratory, University of St Andrews, St Andrews, Fife, Scotland

Guiard, Y., Département de Psychobiologie Experimentale, Institut de Neurophysiologie et de Psychophysiologie, C.N.R.S.INP 3-31, chemin Joseph-Aiguier, 13274 Marseille Cedex 2, France

Hoogland, P. V., Department of Anatomy, Free University, P.O. Box 7161, Amsterdam, The Netherlands

Horn, G., Department of Zoology, University of Cambridge, Cambridge

Innocenti, G. M., Institut d'Anatomie, Université de Lausanne, Rue du Bugnon 9, CH 1011 Lausanne Switzerland

Kemali, M., Laboratorio di Cibernetica CNR, 80072 Arco Felice, Naples, Italy

Kuypers, H.G.J.M., Department of Anatomy Erasmus University, P.O. Box 1738, Rotterdam, The Netherlands

Lazzarini, G., Center for Cerebral Neurophysiology, National Research Council Institute of Neurophysiopathology University of Genoa, Italy

Lhermitte, F., Laboratoire de Neuropsychologie INSERM U.84, Hôpital de la Salpetrière, 47 Boulevard de l'Hôpital, 75634 Paris Cedex 13, France

Lohman, A.H.M., Department of Anatomy, Free University, P.O. Box 7161, Amsterdam, The Netherlands

Maier, V., Institut für Hirnforschung der Universität, August-Forel Strasse 1, $\mathrm{CH}-8008$ Zurich, Switzerland

Manzoni, T., Istituto di Fisiologia Umana, via Grotte di Posatora, 60100, Ancona, Italy

Marzi, C. A., Istituto di Fisiologia, Universita di Pisa, 56100 Pisa, Via S. Zeno 29-31, Pisa, Italy

Meinardi, H., Instituut voor Epilepsiebestreiding, "Meer en Bosch", Achterweg 5, Heemstede, The Netherlands

Meininger, V. Laboratoire de Neuropsychologie INSERM U.84, Hôpital de la Salpetrière, 47 Boulevard de l'Hôpital, 7.5634 Paris Cedex 13, France

Mergner, T., Istituto di Fisiologia Umana, Via S. Zeno 31, 56100 Pisa, Italy
Mohn, G., MRC Unit on Neural Mechanisms of Behaviour, 3 Malet Place, London WC1E $7 \mathrm{JG}$

Moore, J. W., Department of Psychology, Middlesex House, University of Massa chusetts, Amherst, Massachusetts 01002 U.S.A.

Morais, J., Laboratoire de Psychologie experimentale, Université Libre de Bruxelles, Avenue Adolphe Buyl 117, 1050 Bruxelles, Belgium

Morgan, S. C., MRC Unit on Neural Mechanisms of Behaviour, 3 Malet Place, London WC1E $7 \mathrm{JG}$

Mosidze, V. M., Institute of Physiology, Academy of Sciences of the Georgian SSR, Gotua st. N 14, Tbilisi, U.S.S.R.

Moyersoons, F., UCB, Division Pharmaceutique, 68 rue Berkendael, B-1060, Bruxelles Belgium

McQueen, J. K., MRC Brain Metabolism Unit, University Department of Pharmacology, 1 George Square, Edinburgh EH8 9J Z, Scotland

Negrão, N., Laboratorio de Neurofisiologia, Departmento de Fisiologia, Instituto de Ciencias Biomedicas, Universidade de São Paulo, C.P. 4368, São Paulo, S.P. 01000 , Brasil

Overman, W. H., Center for Brain Research, Box 605, University of Rochester, Rochester, New York 14642, U.S.A.

Paillard, J., Institut de Neurophysiologie et de Psychophysiologie, Département de Psychophysiologie Generale, C.N.R.S.INP 4-31, chemin Joseph-Aiguier, 13274 Marseille Cedex 2, France

Pompeiano, O., Istituto di Fisiologia Umana, Via S. Zeno 31, 56100 Pisa, Italy

Poppel, E., Max-Planck-Institut für Psychiatrie, Deutsche Forschungsanstalt für Psychiatrie, 8 Munchen 40, Kraepelinstrasse 2, Postfach 401240, Germany

Preilowski, B., Universität Konstanz, Fachgruppe Psychologie, Postfach 7733, D-7750 Konstanz, B.R.D.

Rizzolatti, G., Istituto di Fisiologia Umana, Universita di Parma, Via Gramsci 14, Parma, Italy 
Rosadini, G., Center for Cerebral Neurophysiology, National Research Council Institute of Neurophysiopathology, University of Genoa, Italy

Rose, S.P.R., Brain Research Group, The Open University, Walton Hall, Milton Keynes

Russell, I. Steele, MRC Unit on Neural Mechanisms of Behaviour, 3 Malet Place, London WC 1E 7JG

Saillant, B., Laboratoire de Neuropsychologie INSERM U.84, Hôpital de la Salpetrière, 47 Boulevard de l'Hôpital, 75634 Paris Cedex 13, France

Sanides, D., Max-Planck-Institut für Biophysikalische Chemie, Postfach 968, D-3400 Gottingen-Nikolausberg, B.R.D.

Savage, G. E., Department of Zoology and Comparative Physiology, Queen Mary College, Mile End Road, London E1 4NS

Schenk, V. W. D., Departments of Neuropathology and Neuroanatomy, Erasmus University, Rotterdam, The Netherlands

Simoni, A., Istituto di Fisiologia Umana, Via San Zeno 29-31, 56100 Pisa, Italy

Singer, W., Max-Planck-Institut für Psychiatrie, Deutsche Forschungsanstalt für Psychiatrie, 8 Munchen 40, Kraepelinstrasse 2, Postfach 401240 , B.R.D.

Spidalieri, G., Istituto di Fisiologia Umana, via Fosato di Mortara 64/b, 44100, Ferrara, Italy

Sprague, J. M., Department of Anatomy, University of Pennsylvania, Philadelphia, Pennsylvania, U.S.A.

Starr, B., Psychology Academic Group, School of Natural Sciences, The Hatfield Polytechnic, P.O. Box 109, College Lane, Hatfield, Herts AL 10 9AB

Stefanko, S. Z., Departments of Neuropathology and Neuroanatomy, Erasmus University, Rotterdam, The Netherlands

Stefano, M. Di, Istituto di Fisiologia Umana, via San Zeno 29-31, 56100 Pisa, Italy

Stock, G., Department of Physiology, University of Heidelberg, Im Neuenheimer Feld 326, D-6900 Heidelberg, B.R.D.
Sturm, V., Department of Physiology, University of Heidelberg, Im Neuenheimer Feld 326, D-6900 Heidelberg, B.R.D.

Swadlow, H. A., Department of Psychology, University of Connecticut, Storrs, Connecticut 06268, and Department of Neurology, Harvard Medical School, Beth Israel Hospital Boston, Massachusetts 02215 , U.S.A.

Van Haelen, H., Laboratoire de Psychologie experimentale, Université Libre de Bruxelles, Avenue Adolphe Buyl 117, 1050 Bruxelles, Belgium

Van Hof, M. W., Department of Physiology 1, Erasmus University, P.O. Box 1738, Rotterdam, The Netherlands

Waxman, S. G., Department of Neurology, Stanford University School of Medicine, Veterans Administration Medical Center, Palo Alto, California 94394, U.S.A.

Weiskrantz, L., Department of Experimental Psychology, University of Oxford, South Parks Road, Oxford OX 1 3UD

Whitteridge, D., Department of Physiology, University of Oxford, South Parks Road, Oxford OX 1 3PT

Wolff, J. R., Max-Planck-Institut für Biophysikalische Chemie, Department Neurobiology, Postfach 968, D-3400 Gottingen-Nickolausberg, B.R.D.

Yeo, C. H., MRC Unit on Neural Mechanisms of Behaviour, 3 Malet Place, London WC1E 7JG

Záborszky, L., 1st Department of Anatomy, Semmelweis University Medical School, Budapest, Hungary

Zeier, H., Swiss Federal Institute of Technology Zurich, Department of Behavioral Science, Turnerstrasse 1, CH-8006 Zurich, Switzerland

Zielinski, K., Nencki Institute of Experimental Biology, 3 Pasteur Street, 02093 Warsaw, Foland

Zihl, J., Max-Planck-Institut für Psychiatrie, Deutsche Forschungsanstalt für Psychiatrie, 8 Munchen 40, Kraepelinstrasse 2, Postfach 401240 , B.R.D. 


\section{PREFACE}

The present book contains a collection of papers culled from the European Brain Behaviour Society's Workshop on The Structure and Function of the Cerebral Commissures, which was held at the Erasmus University Medical School from March 30 to April 2, 1977. The meeting was supported by the Gerrit Jan Mulder Stichting, Rotterdam. Funds were also generously donated by: the European Brain Behaviour Society; the Erasmus University; the Fonds Medische Faculteit Rotterdam; Blydorp Zoo, Rotterdam; Ciba-Geigy; Heineken Breweries; Nefarma; Organon; Unilever and Union Chemique Belge. Both the editors and the contributors wish to express their appreciation to these organisations for making the Workshop possible.

The editors are also grateful to the staff of the Department of Physiology at Rotterdam, especially to Dr Jackie van Hof-van Duin, for dealing with the local arrangements and accommodation so efficiently and pleasantly. We should also like to express our appreciation to Mary James and Hannie Kouer who assisted so ably with the many secretarial problems associated with the preparation of this edition. Finally we are grateful to Mediha Atal for her assistance in the preparation of the cover for the book.

I. Steele Russell

M. W. van Hof

G. Berlucchi 


\title{
INTRODUCTION TO THE BEGINNINGS OF COMMISSURE RESEARCH
}

\author{
G. ATAL RUSSELL and I. STEELE RUSSELL
}

The origins of the work on interhemispheric relations arise from partly philosophical and partly medical concerns with the explanation of the unity of perception or consciousness. As such the various theories and speculations have essentially focused on two principal structures in the brain. In the periphery the optic chiasma was early considered as a mechanism of visual integration. The unity of consciousness was believed to be a product of central integration which was originally thought to occur in the ventricular system; and much later this function was assigned to the commissures.

The earliest written description of the optic chiasma and its connections with the brain in fish was provided by Aristotle (384-322 B.c.). Believing that the brain was little more than an accessory to the heart, he attached no particular significance to the chiasma. Herophilus (fl. c. 300 B.C.) and Erasistratus (fl. c. 260 B.c.), the pioneers of the Alexandrian school of anatomy and medicine, correctly identified the visual role of the optic chiasma. The optic nerves, believed to be hollow tubes were described in Rufus of Ephesus (fl. c. A.D. 98-117) as emerging from the base of the brain and meeting in the chiasma, and then bifurcating laterally to enter both eyes. Aretaeus, the Cappadocian (c. A.D. 81-138 or c. 131-200) described them, however, as completely decussated in the form of the letter $\chi$.

The influence of Galen (A.D. 129-199) in physiology and anatomy, and in particular concerning brain function was a watershed in science. His treatment and interpretation of the visual system were the first attempt to provide a coherent mechanistic explanation of visual perception in anatomical terms. Morphologically he regarded each optic tract not as nerves but as tubular extensions of the brain itself, originating from the lateral ventricles which he termed thalami or cavities. The optic nerves were considered to extend from the brain separately, to come together without any decussation, and to end inside the eyes. There each nerve thins out to form the retina (arachnoeides hitôn) which extends as far as the lens (krystalloeides hitôn).

The function of this system was to provide a hydraulic exchange circuit in the eye to permit the transfer of information from the environment to the brain. Galen believed the ventricles contained a luminous air (pneuma horatikon) which circulated via the channels of the optic nerves to the eye, and from there to the outside where, in the presence of light, it altered or 'stressed' the surrounding air. 
The impression of the object to be perceived was then transmitted to the eye by this 'stressed' air in the form of the Euclidian cone with its base on the object and its apex at the pupil. The two were connected by 'visual rays' which were to be thought of as straight lines analogous to a multitude of fine gossamer threads. Galen regarded the lens as the principal organ of vision or the structure where photoreception occurred. Its alleged function was to act as an exchange membrane where the pneuma could be 'charged' with the images located there by the visual rays (opseis). Visual perception was completed only when the pneuma conveyed these images back to the brain, which was the ultimate site of consciousness. Without the transfer of information by the lens, vision would not be possible.

Galen's views on the optic chiasma were also obscure. Its principal function was to ensure a proper distribution of pneuma from the brain to both eyes. During monocular vision it acted to redeploy all of the available pneuma to the open eye, thus to compensate for the loss of one receptor by doubling the power of the other. At the same time the chiasma served to prevent diplopia.

Further developments in our understanding of the function of the optic chiasma had to wait until the early beginnings of modern physiology and the rise of experimental scientific enquiry. This began with the recognition of the eye as an optic instrument in Islamic science. A significant feature of Arabic treatises and books on medicine and physics is their detailed description of the structure and function of the eye. What is perhaps more important is the fact that for the first time in history they use detailed illustrations of the eye, optic nerves, and the brain. For example, Hunain ibn Ishāq (Johannitius, A.D. 809-877) produced a diagram of the eye (see figure I.1) that was not only remarkable for its detail and clarity, but represents a genre that powerfully influenced all early European diagrams of the eye by Roger Bacon, Pecham, Witello, and even da Vinci and Vesalius. Such early Arab physicians as ibn Ishāq were, however, adherents of the emanation doctrines as well as being assiduous practitioners of Galenic principles.

The most comprehensive and systematic alternative to classical optical theories was formulated by the mathematician-physicist Ibn al-Haytham (Alhazen, A.D. 965-1039) who had a profound influence on Western science. His principal work on optics (Kitab al-Manazir) was already translated into Latin by the thirteenth century and together with Risner's printed edition, Opticae thesaurus (1572) dominated European thought until the seventeenth century. It is for this reason that he is known as the father of ophthalmology.

The essential feature of Ibn al-Haytham's system is his theory of direct vision and his uncompromising rejection of emanation theory. His statement that the act of vision is accomplished by means of light rays coming from external objects and entering the eye .... and the belief of those who think that something comes out of the eye is false' is both trenchant and clear. Of paramount importance was his belief that an unqualified reliance on naive sensory observation was inherently undesirable. He gives as an example of this the illusion of seeing the moon move when it is observed in the wake of morning clouds. True scientific knowledge, Ibn al-Haytham insisted, could only come from anchoring all observations to 


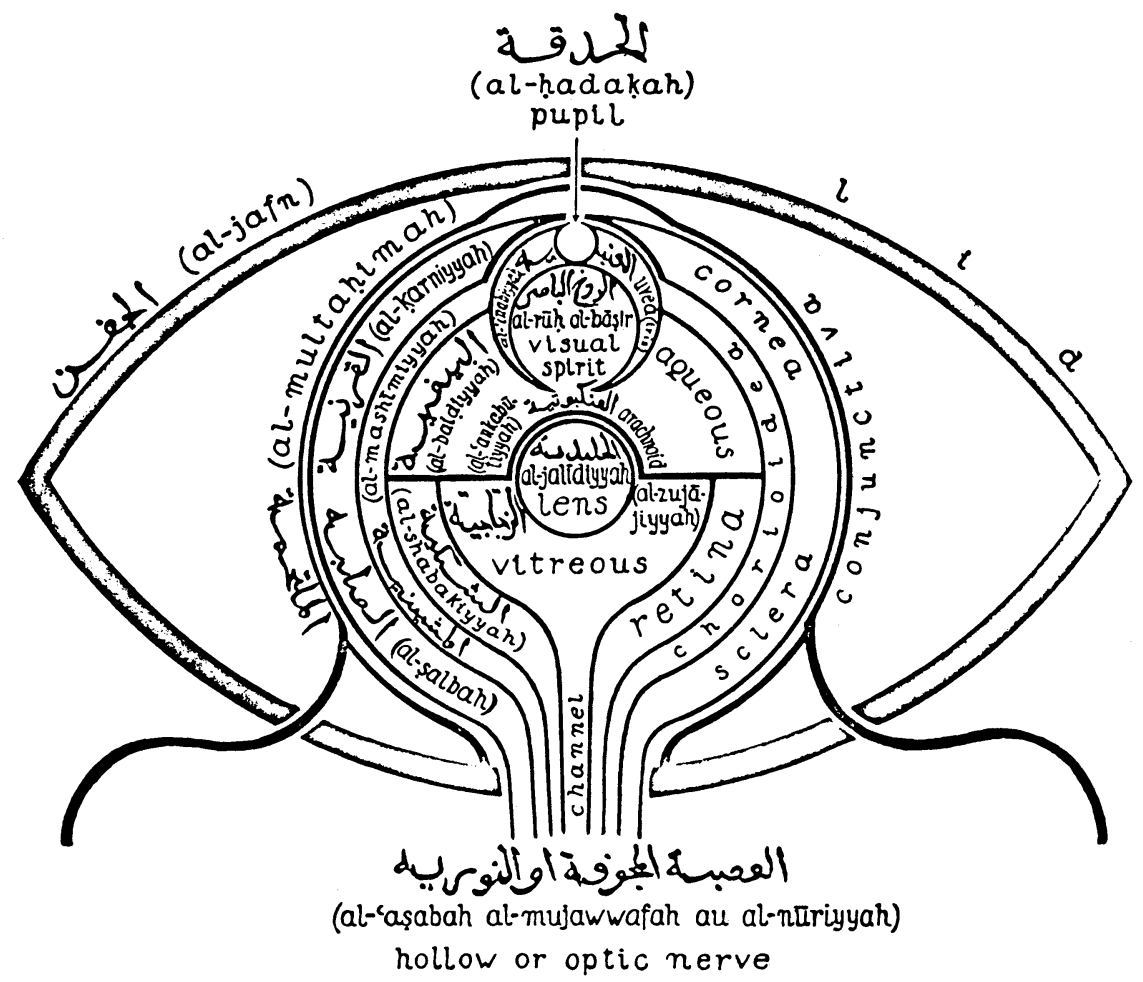

Figure I.1 Adapted from a diagram of the eye contained in a manuscript written by Hunain ibn Ishāq entitled Ten Treatises on the Structure of the Eye, its Diseases and their Treatment. The approximate date of the original manuscript is A.D. 860. The manuscript in which the figure was found was dated at A.D. 1196. The text was preserved in Europe in pseudonymous Latin translations of such great plagiarists as Constantine, The African

quantitative measurement or by finding systematic agreement among several unrelated observations.

Nowhere is this better illustrated than with his investigations of the linear transmission of light. He used a dark chamber with a small aperture in one wall to provide a narrow point source of light. Filling the room with dust allowed the beam of light to be both visualised and tested for linearity against a rule. Similarly, stretching a thread along the path of a light beam in a dust-free chamber was shown to give the same results. Finally using an angled light from the wall to the floor he measured the height of the beam at various distances from the wall. By this method it was shown that the path taken by the light was the hypoteneuse of a triangle where the remaining sides were the wall and floor respectively.

Considering the nature of light, Ibn al-Haytham concluded that it was a form of energy related to heat because the sun's rays are both luminous and warm, as is light from fire. Furthermore he demonstrated that when light rays are reflected by a concave mirror they will burn objects placed at the focus, dependent on the intensity of the light. The effect of such intense lights on the eye is both to blur 
vision and to induce pain, which indicated to Ibn al-Hay tham that vision could only result from light rays entering the eye from the outside world. The emission of the eye's own rays could not be responsible for the experience of pain. Similarly he argued that the phenomenon of visual after-images was due to the external bright light producing a temporary injury to the eye.

In optics he made significant contributions to both catoptrics and dioptrics. Not only did he experimentally confirm the first law of reflection, but he was responsible for the second law that the incident, normal and reflected rays always lie in the same plane. His major contribution was, however, his experimental studies of light refraction. He was the formulator of the first law of refraction and part-discoverer of the second law. By careful and systematic observation he established the fact that the angle of incidence is always greater than the angle of refraction. Further, he noted that when the angle of incidence is less than $20^{\circ}$ the ratio of the two angles is constant. For angles of incidence greater than this the ratio was variable. Despite his familiarity with trigonometric tables he did not compare the sines of the angles, and thus left the complete formulation of the second law of refraction to Snell to complete in 1621. Ibn al-Haytham was mainly limited in studies of dioptrics to considering the refraction of light from air to water. However, preliminary observations on the refraction of light by water-filled glass bottles led him to explore the mathematical properties of magnifying lenses, which due to the inadequacies of the technology of his day were not taken further. Finally he performed numerous experiments with the pin-hole camera, where he first demonstrated how the image of an external candle was inverted on the screen inside the chamber.

In his treatment of the eye Ibn al-Haytham for the first time gave us the modern synthesis of anatomy and physical optics. His description of the structure and mechanisms of the eye is a model of clarity and attention to detail, suggesting that his knowledge of the anatomy of the eye came from dissection and detailed observation. In particular his exact description of the lens illustrates this point. To Ibn al-Haytham the round shape of the lens with its biconvex lateral appearance resembled a lentil grain. He further noted that the anterior surface of the lens was relatively flat compared with the posterior surface which has a much shorter radius of curvature. The Arabic word adasa (lentil) was translated into Latin as lenticula which is the origin of the English word lens. Another example of the early diffusion of Arabic influences to the West is seen with the word cornea. The transparent anterior surface of the eye was called al-qarniyya in Arabic to refer to a protrusion or horn. This was conveyed directly into Latin as cornea with no attempt being made to translate it.

Ibn al-Haytham likened the eye to a modified 'dark chamber' or pin-hole camera, where the pupil acts as an aperture to project an upright image on the back of the posterior chamber of the eye. Despite his pioneering investigations into refraction he totally failed to appreciate the true function of the lens. Instead he believed it was that part of the eye where visual sensations are first experienced as is the case when intense light induces pain. Light rays were refracted by the vitreous humour in such a way as to form an upright image. This image was created by the perpendicular light rays from the object to the eye so that each point of 
the object has a corresponding spatially organised point on the retinal image. This image or pattern of stimulation was thought to be preserved as it travelled in the hollow optic nerve to the brain where conscious perception of the object occurred. These ideas of Ibn al-Haytham clearly represent one of the earliest formulations of the concept of topographic retinal projection to the cerebrum.

Furthermore this notion of retinal information having a punctate organisation in the optic nerve was a cardinal assumption in his explanation of both the unity of perception and the function of the optic chiasma (see figure I.2). He believed the chiasma to be an association nerve (al-asaba al-jawfa al-mushtarika) where the contents of the two optic nerves came together and were mixed. This enabled the separate images from the two eyes to be superimposed and establish an exact match to generate a single fused image which in turn was conveyed to the brain resulting in a single visual experience.

An alternative view of the chiasma was provided by ibn Sina (Avicenna, A.D.

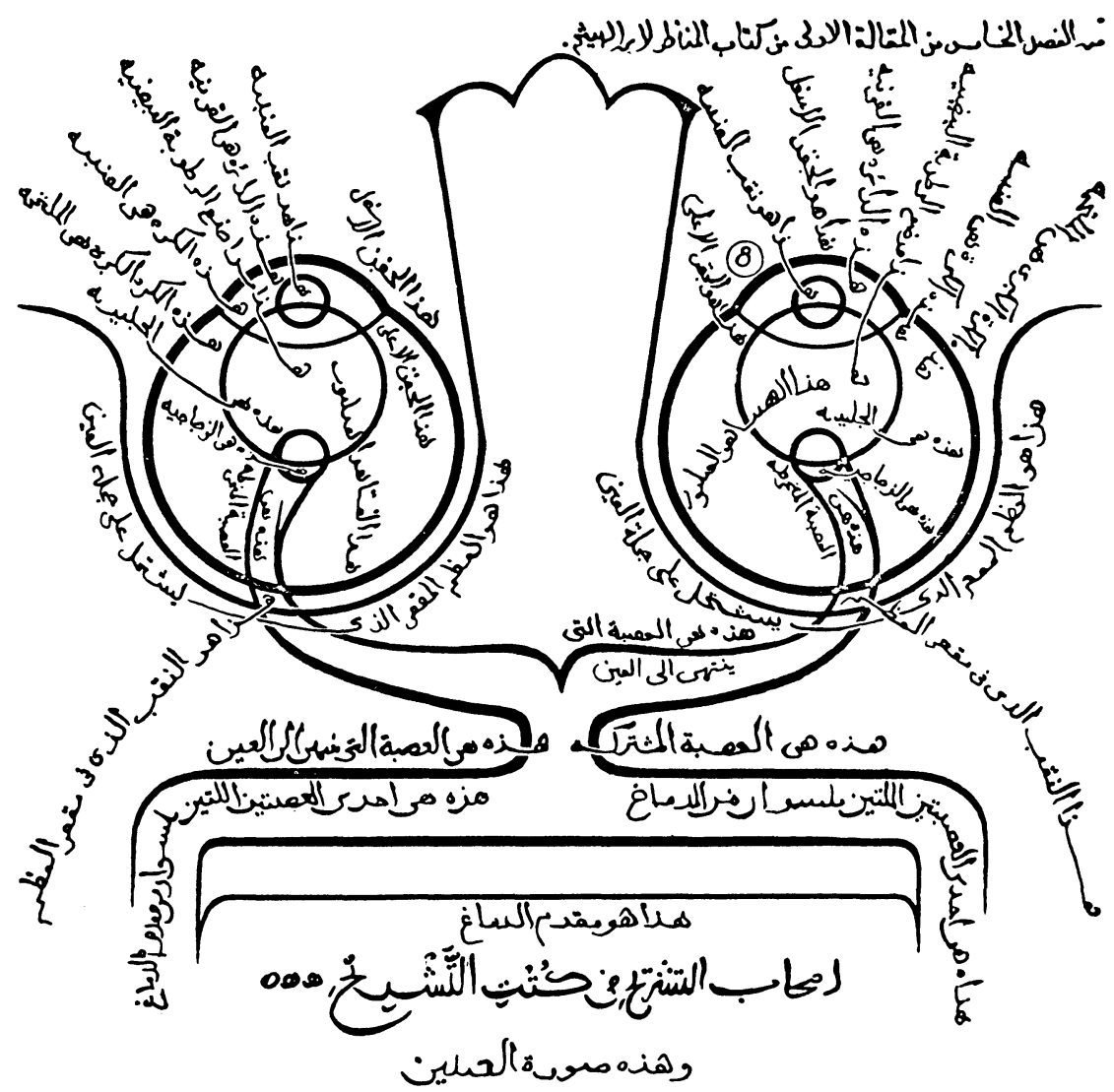

Figure I.2. Drawing adapted from a diagram of the visual system from the oldest copy of the Kitab al-manazir by Ibn al-Haytham. Manuscript dated A.D. 1083 in the possession of the Fatih Library, Istanbul. For identification of parts represented see Figure 8, p. 41 in S. Polyak, The Retina 
980-1037) the great savant from Bukhara in Turkistan. In contrast to Ibn alHaytham he believed the optic nerves in the chiasma to be completely crossed (see figure I.3) such that the separate images from the eyes are conveyed to opposite lateral ventricles. He provided the answer to the problem of the unity of consciousness by having the third and fourth ventricles act as association chambers to unite the separate images.

Thus by the end of the eleventh century both a peripheral and a central theory of the unity of consciousness had been promulgated in terms that were to remain

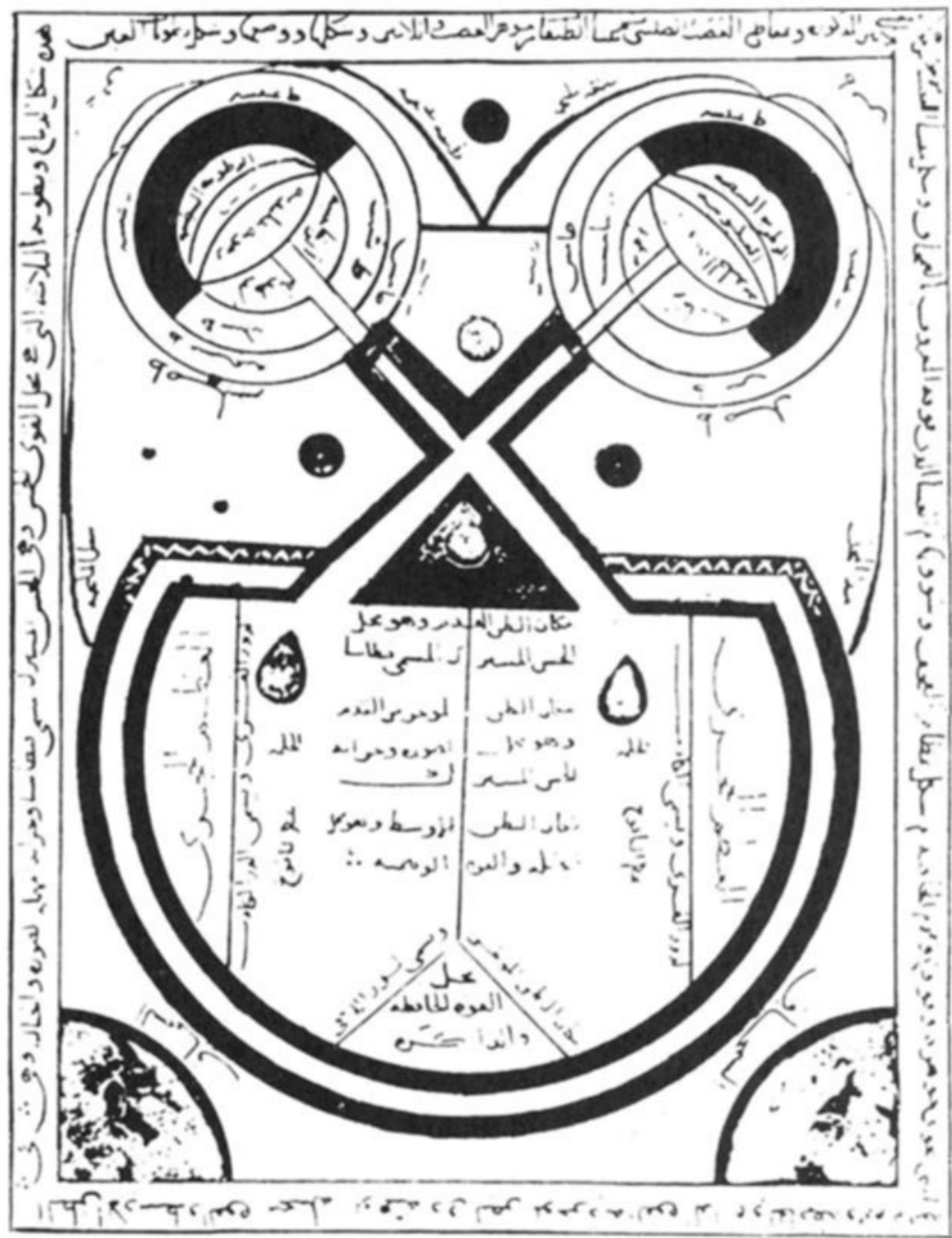

Figure I.3. Diagram of the visual system from a manuscript by Khalifa $c$ A.D. 1266. The upper part shows the two lateral ventricles, with the third and fourth ventricles of the brain in the midline. The complete crossing of the optic nerves in the chiasma is shown. See S. Polvak. The Vertebrate Visual System 
essentially unchanged for the next 600 years. It was not until Descartes published his Traité de l'Homme in 1686 that a neural alternative was proposed to the ventricular hydraulic model. With the advantages of the new knowledge in optics and mathematics Descartes was able to reformulate Ibn al-Haytham's ideas of projection in modern form. The pineal gland then became the neural site where binocular integration occurred during vision. It was not until 1903 that the central integrating role of the corpus callosum was discovered (Immamura, 1903).

\section{REFERENCES}

Clarke, E. and O'Malley, C. D. (1968). Aretaeus, the Cappadocian, p. 282; Aristotle, p. 9, The Human Brain and Spinal Cord: A Historical Study Illustrated by Writings from Antiquity to the Twentieth Century. University of California Press, Berkeley

Crombie, A. C. (1967). The mechanistic hypothesis and the scientific study of vision. Proc. $R$. Microsc. Soc., 2(1), 12-22

Galen (129-199). The Eyes, On the usefulness of the parts of the body. De usu partium, translated by M. T. May (1968). Cornell University Press, Ithaca; II, X, 463-504

Siegel, R. E. (1970). Galen on Sense Perception: His doctrines, observations, and experiments on vision, hearing, smell, taste, touch, and pain, and their historical sources. Karger, Basel

Hunayn b. Ishaq (809-877). The Book of Ten Treatises on the Eye, ed. and trans.

M. Meyerhof (1928). Government Press, Cairo

Ibn al-Haytham (965-1039).

Grant, E. (ed.) (1974). A Source Book in Medieval Science. Harvard University Press, Cambridge Massachusetts, 376-432.

Lindberg, D. C. (1967). Alhazen's theory of vision and its reception in the West. ISIS , 581, 327-41.

Lindberg, D. C. (1976). Theories of Vision from al-Kindi to Kepler. University of Chicago Press, Chicago

Nazif, M. (1942-43), Al-Hasan ibn al-Haytham buhuthuhu wa-kushūfuhu albasariyya (Ibn al-Haytham: His Optical Researches and Discoveries) 2 vols, Cairo

Omar, S. B. (1977). Ibn al-Haytham's Optics: A Study of the Origins of Experimental Science. Bibliotheca Islamica, Chicago, iii, 59-100

Sabra, I. A. (1972). 'Ibn al-Haytham', Dict. of Scient. Biogr., VI, 189-210.

Ibn Sina (980-1037). Psychologie d'Ibn Sina (Avicenne) d'apres son oeuvre as-Sifa, ed. Jan Bakoš. (French trans. and Arabic text) (1956) 2 vols, Prague, Book 6, Part 4

Rahman, F. (1952). Avicenna's Psychology: An English translation of the Kitab al-Najăt. Book III, vi. Oxford University Press, London

Immamura, A. (1903). Über die kortikalen Storungen des Sehaktes und die Bedeutung des Balkens. Pflügers Arch., 100, 495-531

Polyak, S. (1941). The Retina, University of Chicago Press, Chicago Part II, vii-ix

Polyak, S. (1957). The Vertebrate Visual System. University of Chicago

Press, Chicago Part I, i, 1-4; ii, 1-6 